\title{
PREVALENSI PENCABUTAN GIGI PERMANEN DI POLIKLINIK GIGI PUSKESMAS KALUKU BODOA DI KOTA MAKASSAR
}

\author{
Hj. Nurhaeni, Asridiana
}

\begin{abstract}
ABSTRAK
Puskesmas adalah suatu organisasi fungsional yang menyelenggarakan upaya kesehatan yang bersifat menyeluruh, terpadu, merata dan dapat diterima dan terjangkau oleh masyarakat dan menggunakan hasil pengembangan ilmu pengetahuan dan teknologi tepat guna dengan biaya yang dapat ditanggung oleh pemerintah dan masyarakat. Pencabutan gigi atau yang dalam ilmu kedokteran gigi biasa disebut ekstraksi gigi adalah suatu prosedur dental mengeluarkan gigi dari soketnya. Tujuan dari penelitian ini adalah untuk mengetahui Prevalensi Pencabutan Gigi permanen di Poliklinik Gigi Puskesmas Kaluku Bodoa Kota Makassar. Jenis penelitian ini adalah penelitian observasional dengan rancangan penelitian berupa penelitian deskriptif dengan menggunakan desain cross sectional. Populasi dalam penelitian ini adalah seluruh pasien yang datang melakukan pencabutan gigi di Puskesmas Kaluku Bodoa Kota Makassar. Pengambilan sampel dalam penelitian ini dengan cara total sampling yaitu mengambil sampel yang sesuai dengan anggota populasi yaitu berjumlah 75 orang. Hasil dari penelitian menunjukkan bahwa tindakan pencabutan gigi permanen terhadap perempuan sebanyak $45(60 \%)$ dan laki-laki sebanyak 30 (40\%). Prevalensi Pencabutan Gigi Permanen berdasarkan kelompok usia pasien adalah usia 35-44 tahun memiliki frekuensi pencabutan gigi yang paling banyak yaitu 22 kasus $(29,3 \%)$.
\end{abstract}

Kata kunci: Gigi, Pencabutan, Prevalensi

\section{PENDAHULUAN}

Puskesmas adalah suatu organisasi fungsional yang menyelenggarakan upaya kesehatan yang bersifat menyeluruh, terpadu, merata dan dapat diterima dan terjangkau oleh masyarakat dan menggunakan hasil pengembangan ilmu pengetahuan dan teknologi tepat guna dengan biaya yang dapat ditanggung oleh pemerintah dan masyarakat. Upaya kesehatan tersebut diselenggarakan dengan menitikberatkan pada pelayanan untuk masyarakat luas, guna mencapai derajat kesehatan yang optimal tanpa mengabaikan mutu pelayanan kepada perorangan (Depkes, 2000).

Prevalensi adalah bagian dari studi epidemiologi yang membawa pengertian jumlah orang dalam populasi yang mengalami penyakit, gangguan atau kondisi tertentu pada suatu tempoh waktu dihubungkan dengan besar populasi dari mana kasus itu berasal. Prevalensi sepadan dengan insidensi dan tanpa insidensi penyakit maka tidak akan ada prevalensi penyakit. Insidensi merupakan jumlah kasus baru suatu penyakit yang muncul dalam satu periode waktu dibandingkan dengan unit populasi tertentu dalam periode tertentu.Insidensi memberitahukan tentang kejadian kasus baru.Prevalensi memberitahukan tentang derajat penyakit yang berlangsung dalam populasi pada satu titik waktu (Timmereck, 2001). Dalam hal ini prevalensi setara dengan insidensi dikalikan dengan ratarata durasi kasus (Lilienfeld dan Lilienfeld, 2001 dalam Timmereck, 2004).

Pencabutan gigi atau yang dalam ilmu kedokteran gigi biasa disebut ekstraksi gigi adalah suatu prosedur dental mengeluarkan gigi dari soketnya. Pencabutan gigi dikatakan ideal jika dalam pelaksaannya tidak disertai rasa sakit, trauma yang terjadi pada jaringan sekitar gigi seminimal mungkin, luka pencabutan dapat sembuh secara normal dan tidak menimbulkan permasalahan pasca pencabutan. (Sanghai S, 2009)

Gigi perlu dicabut karena berbagai alasan, beberapa di antaranya adalah persistensi gigi sulung dan supernumerary teeth/crowding teeth, penyakit periodontal yang parah, gigi yang fraktur dan gigi yang menyebabkan abses periapikal, gigi dengan karies yang dalam, gigi yang terletak pada garis 
fraktur, gigi impaksi, tujuan ortodontik, tujuan prostetik, sebelum perawatan radioterapi, pencabutan profilaksis, sisa akar. (Loekman M; 2007)

Sementara semua kontraindikasi baik lokal maupun sistemik dapat menjadi relatif atau mutlak (absolut) tergantung pada kondisi umum pasien. Ketika kontraindikasi itu mutlak, perawatan ekstra perlu dilakukan sebelum pencabutan gigi untuk menghindari berbagai resiko yang dapat terjadi pada pasien. Beberapa kontraindikasi pencabutan gigi penyakit periapical terlokalisir, keberadaan infeksioral, pericoronitis akut, penyakitganas, pencabutan gigi pada pasien terapi radiasi, penyakit sistemik seperti diabetes, hipertensi, penyakit jantung, pasien terapi steroid, kehamilan, diskrasia darah, pasien terapi antikoagulan, gondok beracun, penyakit kuning. (Balaji SM, 2007)

\section{METODE PENELITIAN}

Jenis penelitian ini adalah penelitian observasional dengan rancangan penelitian berupa penelitian deskriptif dengan menggunakan desain cross sectional. Populasi dalam penelitian ini adalah seluruh pasien yang datang melakukan pencabutan gigi di Puskesmas Kaluku Bodoa Kota Makassar. Dari pencatatan laporan bulanan Puskesmas Kaluku Bodoa Kota Makassar, lebih dari 75 orang yang datang melakukan pencabutan gigi tiap bulannya. Pengambilan sampel dalam penelitian ini dengan cara total sampling yaitu mengambil sampel yang sesuai dengan anggota populasi yaitu berjumlah 75 orang. Penelitian dilaksanakan di Ruang Poliklinik Gigi Puskesmas Kaloko Bodoa Kota Makassar. Penelitian ini dilaksanakan pada Oktober November 2019. Jenis data yang digunakan adalah data primer dan data sekunder. Alat dan bahan penelitian yang digunakan adalah Alat Diagnostik. Data yang akan didapat dalam penelitian ini akan disajikan dengan menggunakan Analisa Data Manual. Yakni data dikumpulkan dengan pengamatan langsung menggunakan instrumen penelitian lalu data digambarkan secara deskriptif sebagaimana adanya.

\section{HASIL PENELITIAN}

Penelitian ini dilakukan di Puskesmas Kaluku Bodoa Kota Makassar dengan subyek penelitian adalah seluruh ditangani di poli gigi Puskesmas Kaluku Bodoa Kota Makassar yang merupakan pencabutan gigi permanen.

Tabel 1. Distribusi Frekuensi Pencabutan Gigi Berdasarkan Jenis Kelamin

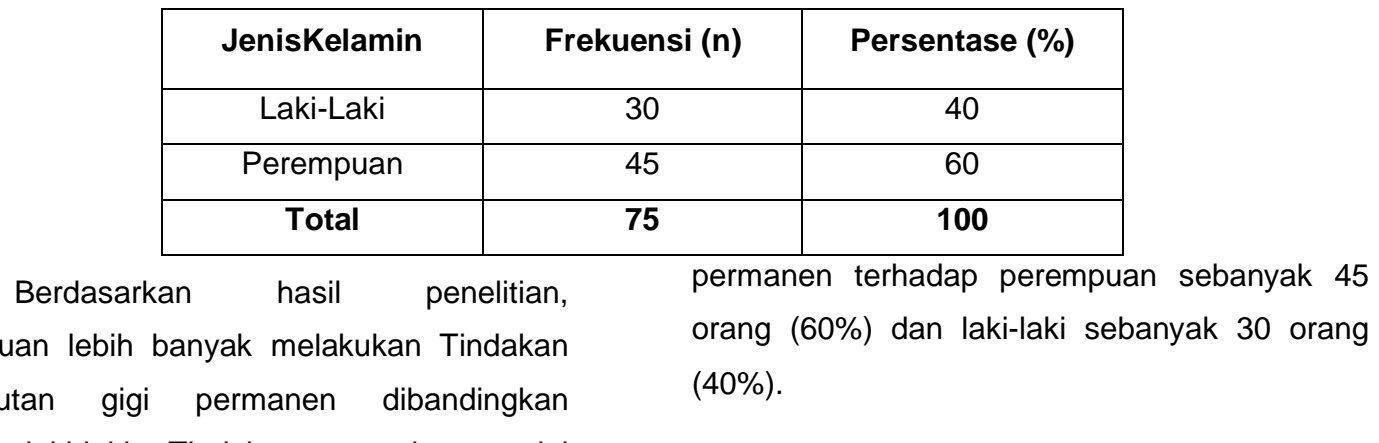

dengan laki-laki. Tindakan pencabutan gigi 
Tabel 2. Distribusi Frekuensi Pencabutan Gigi Berdasarkan Usia Pasien

\begin{tabular}{|c|c|c|}
\hline Usia Pasien & Frekuensi (n) & Persentase (\%) \\
\hline $10-14$ tahun & 2 & 2,7 \\
\hline $15-24$ tahun & 8 & 10,7 \\
\hline $25-34$ tahun & 16 & 21,3 \\
\hline $35-44$ tahun & 22 & 29,3 \\
\hline $45-54$ tahun & 12 & 16 \\
\hline $55-64$ tahun & 10 & 13,3 \\
\hline$>65$ tahun & 5 & 6,7 \\
\hline Total & $\mathbf{7 5}$ & $\mathbf{1 0 0 \%}$ \\
\hline
\end{tabular}

Kelompok usia 35-44 tahun memiliki frekuensi pencabutan gigi yang paling banyak yaitu 22 kasus $(29,3 \%)$, kemudian diikuti dengan kelompok usia 25-34 tahun 16 kasus $(21,3 \%)$, kelompok usia 45-54 tahun 12 kasus (16\%), kelompok usia 55-64 tahun 10 kasus (13,3\%), kelompok usia 15-24 tahun 8 kasus $(10,7 \%)$, kelompok usia $>65$ tahun 5 kasus $(6,7 \%)$ dan frekuensi pencabutan gigi yang paling rendah ada dikelompok usia10-14 tahun yaitu sebanyak 2 kasus( $2,7 \%)$.

Tabel 3. Distribusi Frekuensi Pencabutan Gigi Berdasarkan Jenis Gigi Permanen

\begin{tabular}{|c|c|c|}
\hline Jenis Gigi & Frekuensi (n) & Persentase \\
\hline Molar I RahangAtas & 7 & 9 \\
\hline Molar II RahangAtas & 13 & 17 \\
\hline Molar I Rahang Bawah & 28 & 37 \\
\hline Molar II Rahang Bawah & 19 & 26 \\
\hline Molar III Rahang Bawah & 8 & 11 \\
\hline TOTAL & 75 & $100 \%$ \\
\hline
\end{tabular}

Dari 75 kasus pencabutan gigi permanen di Puskesmas Kaluku Bodoa Kota Makassar, jenis gigi permanen yang paling banyak dicabut ialah molar pertama rahang bawah sebanyak 28 gigi (37\%), kemudian gigi molar kedua rahang bawah sebanyak 19 gigi (26\%), gigi molar kedua rahang atas sebanyak 13 gigi (17\%), gigi molar kedua rahang bawah sebanyak 8 gigi (11\%), molar pertama rahang atas sebanyak 7 gigi (9\%). 
abel 4. Distribusi Frekuensi Pencabutan Gigi Berdasarkan Indikasi Pencabutan

\begin{tabular}{|l|c|c|}
\hline Indikasi Pencabutan & $\begin{array}{c}\text { Frekuensi } \\
\text { (n) }\end{array}$ & $\begin{array}{c}\text { Persentase } \\
\text { (\%) }\end{array}$ \\
\hline Karies Gigi & 30 & 40 \\
\hline Penyakit Periodontal & 40 & 53 \\
\hline Keperluan Ortodontik & 2 & 3 \\
\hline Keperluan Prostetik & 0 & 0 \\
\hline Impaksi & 0 & 0 \\
\hline Fraktur & 3 & 4 \\
\hline \multicolumn{1}{|c|}{ TOTAL } & $\mathbf{7 5}$ & $\mathbf{1 0 0 \%}$ \\
\hline
\end{tabular}

Dari hasil penelitian, ditemukan bahwa indikasi pencabutan gigi yang paling sering disebabkan oleh penyakit periodontal yakni sebanyak 40 kasus (53\%), kemudian disebabkan karena karies sebanyak 30 kasus (40\%), oleh karena fraktur gigi sebanyak 3 kasus (4\%), pencabutan gigi karena keperluan orthodontic sebanyak 2 kasus (3\%). Indikasi karena keperluan prostetik dan impaksi tidak ditemukan dalam 75 kasus pencabutan gigi permanen di Puskesmas Kaluku Bodoa Kota Makassar.

Tabel 5. Frekuensi Pencabutan Gigi Permanen Berdasarkan Jenis Kelamin dan Usia

\begin{tabular}{|c|c|c|c|c|c|c|c|c|}
\hline \multirow{2}{*}{$\begin{array}{c}\text { Jenis } \\
\text { Kelamin }\end{array}$} & $10-14$ & $15-24$ & $25-34$ & $35-44$ & $45-54$ & $55-64$ & $>65$ & \\
\hline Laki-Laki & 0 & 3 & 10 & 12 & 6 & 7 & 2 & 30 \\
\hline Perempuan & 2 & 5 & 6 & 20 & 6 & 3 & 3 & 45 \\
\hline Total & 2 & 8 & 16 & 22 & 12 & 10 & 5 & 75 \\
\hline
\end{tabular}

Dari 75 kasus pencabutan gigi permanen yang dilakukan di Puskesmas Kaluku Bodoa Kota Makassar, frekuensi pencabutan gigi permanen berdasarkan jenis kelamin dan kelompok usia yang melakukan pencabutan gigi permanen pada perempuan menunjukan frekuensi yang paling tinggi dikelompok usia 35-44 tahun yakni sebanyak 22 kasus, kemudian diikuti dengan kelompok usa 25-34 tahun sebanyak 16 kasus, kelompok usia 45-54 tahun sebanyak 12 kasus, kelompok usia 15-24 tahun sebanyak 8 kasus, kelompok usia 55-64 tahun sebanyak 10 kasus, kelompok usia $>65$ tahun sebanyak 5 kasus dan frekuensi paling rendah ada di kelompok usia10-14 tahun sebanyak 2 kasus.

Frekuensi pencabutan gigi permanen berdasarkan jenis kelamin dan kelompok usia yang melakukan pencabutan gigi permanen pada laki-laki menunjukan frekuensi paling tinggi pada kelompok usia 35-44 tahun yakni sebanyak 12 kasus, kemudian pada kelompok usia 25-34 tahun sebanyak 10 kasus, kelompok usia 55-64 tahun sebanyak 7 kasus, kelompok usia 4554 tahun sebanyak 6 kasus, kelompok usia 15-24 tahun sebanyak 3 kasus, kelompok usia >65 tahun sebanyak 2kasus dan frekuensi paling rendah di kelompok usia 1014 tahun. 
Tabel. 6. Gambaran Pencabutan Gigi Permanen Berdasarkan Jenis Kelamin dan Indikasi Pencabutan

\begin{tabular}{|c|c|c|c|c|c|}
\hline \multirow{2}{*}{$\begin{array}{c}\text { Jenis } \\
\text { Kelamin }\end{array}$} & \multicolumn{4}{|c|}{ Indikasi Gigi dicabut } & Total \\
\cline { 2 - 5 } & Karies & $\begin{array}{c}\text { Penyakit } \\
\text { Periodontal }\end{array}$ & $\begin{array}{c}\text { Keperluan } \\
\text { Orthodontik }\end{array}$ & Fraktur & \\
\hline Laki-Laki & 10 & 20 & 0 & 0 & 30 \\
\hline Perempuan & 20 & 22 & 2 & 3 & 45 \\
\hline Total & 30 & 40 & 2 & 3 & 75 \\
\hline
\end{tabular}

Dari 75 pasien pencabutan gigi permanen yang diteliti, jika dibandingkan antara jenis kelamin dan indikasi gigi dicabut, terlihat penyakit periodontal merupakan indikasi yang paling banyak melatar belakangi sehingga gigi permanen dicabut. Pada indikasi karena penyakit periodontal perempuan lebih banyak melakukan pencabutan gigi permanen yaitu sebanyak 22 kasus dan laki-laki sebanyak 20 kasus. Indikasi pencabutan gigi karena karies pada perempuan sebanyak 20 kasus dan lakilaki sebanyak 10 kasus. Indikasi pencabutan gigi karena fraktur pada laki-laki tidak ditemukan pada penelitian ini, sedangkan perempuan hanya sebanyak 3 kasus saja. Pada indikasi untuk keperluan orthodontic juga tidak ditemukan pada laki-laki, hanya ditemukan pada perempuan yaitu sebanyak 2 kasus.

\section{PEMBAHASAN}

Pencabutan gigi merupakan suatu pencabutan gigi pencabutan gigi proses pengeluaran gigi dari alveolus, dimana pada gigi tersebut sudah tidak dapat dilakukan perawatan lagi. Tindakan ini merupakan hal yang biasa dilakukan dengan prosedur rutin pada pasien, oleh karena pencabutan gigi merupakan cara termudah dan terbaik untuk menghilangkan sakit gigi apabila gigi tersebut tidak dapat dipertahankan lagi. Distribusi pencabutan gigi berdasarkan jenis kelamin, perempuan lebih banyak melakukan pencabutan gigi dibandingkan dengan laki-laki. Perempuan sebanyak 45 kasus (60\%) dan laki-laki sebanyak 30 kasus (40\%). Hasil penelitian ini sesuai dengan penelitian Rinda Sulistyanti di Poliklinik
Gigi dan Mulut RSUP Prof. Dr. R. D. Kandou Manado (2010) yakni perempuan lebih banyak melakukan pencabutan gigi permanen $(53,5 \%)$ dari pada laki-laki (46,\%). Dixit dkk (2010) di Nepal juga mendapatkan hal yang sama yakni perempuan lebih banyak melakukan pencabutangigi permanen (54,0\%) dibandingkan dengan laki-laki (46,0\%). Hasil yang berbeda dilaporkan oleh Ryan Irwanto Tunggal di Rumah Sakit Tingkat III TNI AD Robert Wolter Mongisidi (2012) yakni laki-laki lebih banyak melakukan pencabutan gigi permanen dibandingkan perempuan (49,03\%).

Kehilangan gigi ini dipengaruhi oleh berbagai faktor. Perbedaan populasi akan memberikan hasil yang berbeda. Hasil penelitian ini menunjukkan bahwa perempuan memiliki angka pencabutan gigi yang lebih tinggi dibandingkan pada laki-laki, hal ini mungkin karena perempuan lebih sering mengkonsumsi makanan atau minuman manis. Makanan dan minuman yang mengandung gula akan menurunkan $\mathrm{pH}$ plak dengan cepat sehingga dapat menyebabkan demineralisasi email dan berujung pada kerusakan atau kehilangan gigi jika hal tersebut terus menerus terjadi di dalam rongga mulut. Faktor lain yang mempengaruhi tingginya angka kehilangan gigi pada perempuan yakni perempuan akan mengalami menopause sehingga akan terjadi defisiensi hormone estrogen. Hormon estrogen merupakan regulator pertumbuhan dan homeostasis tulang yang penting. Berkurangnya hormon estrogen ini akan mempengaruhi densitas tulang, termasuk tulang alveolar yang menopang gigi geligi. (SudoyoAW dkk, 2009) 


\section{Berdasarkan pengelompokan usia} pasien yang melakukan pencabutan gigi permanen, didapatkan bahwa kelompok usia 3544 tahun memiliki frekuensi pencabutan gigi permanen yang paling tinggi yakni 22 kasus $(29,3 \%)$ dan yang paling rendah ada di kelompok usia 10-14 tahun yakni 2 kasus $(2,7 \%)$. Hasil ini tidak jauh berbeda dengan yang dilaporkan Dixit, dkk tahun (2010) di Nepal bahwa usia>30 tahun $(79,1 \%)$ memiliki frekuensi pencabutan gigi lebih tinggi dibandingkan dengan kelompok usia $\leq 30$ tahun $(20,9 \%)$. Tingginya pencabutan gigi permanen pada kelompok usia 35-44 tahun dapat disebabkan oleh beberapa faktor salah satunya karena telah terjadi akumulasi deposit plak, kalkulus, peningkatan jumlah poket, serta mulai kehilangan jaringan dan resorpsi tulang yang biasanya terjadi sejak usia $>35$ tahun.

Jenis gigi permanen yang paling banyak dicabut ialah gigi molar pertama rahang bawah 28 kasus (37\%) dan gigi molar pertama atas rahang bawah merupakan gigi permanen yang paling sedikit dicabut 7 kasus (9\%). Hasil ini serupa dengan yang dilaporkan Ryan Irwanto Tunggal dalam penelitiannya di Rumah Sakit Tingkat III TNI AD Robert Wolter Monginsidi Manado (2012) bahwa gigi molar pertama rahang bawah memiliki frekuensi pencabutan gigi yang paling tinggi $(20,86 \%)$ dan yang paling rendah ialah gigi caninus rahang bawah $(1,19 \%)$. Sharafatdkk (2008) di Jordan juga melaporkan bahwa molar pertama rahang bawah memiliki frekuensi yang paling tinggi $(15,53 \%)$ dan gigi caninus rahang bawah memiliki frekuensi pencabutan yang paling rendah $(3,11 \%)$.

Menurut Itjiningsih, gigi molar pertama rahang bawah rawan untuk mengalami kerusakan karena merupakan gigi permanen yang pertama erupsi di dalam rongga mulut. Selain itu, gigi molar merupakan gigi yang memiliki pit dan fissure pada permukaan oklusal sehingga memudahkan plak terselip jika tidak dibersihkan dengan baik. Plak ini mengandung bakteri yang merupakan tahap awal terbentuknya karies atau penyakit periodontal. Gigi kaninus rahang bawah memiliki frekuensi pencabutan yang paling rendah disebabkan karena gigi kaninus merupakan gigi yang paling panjang di dalam mulut. Gigi kaninus juga merupakan gigi anterior sehingga kesehatan gigi anterior biasanya lebih mendapat perhatian sebagai factor estetik seseorang. (Kid EAM, dkk, 2012)

Hasil penelitian pada pencabutan gigi permanen menunjukan bahwa indikasi pencabutan gigi yang paling sering disebabkan karena penyakit periodontal (53\%). Hasil yang serupa juga dilaporkan oleh Jun Aida di Jepang (2006), penyakit periondontal menjadi indikasi yang paling tinggi menyebabkan gigi dicabut yakni sebanyak 3.812 kasus $(41,8 \%)$ dari total 9115 kasus. Etiologi penyakit periodontal ini ada 2 faktor, yakni faktor primer dan factor sekunder. Faktor primer penyakit periodontal ialah bakteri sedangkan factor sekunder dapat bersifat local atau sistemik

Frekuensi pencabutan gigi permanen berdasarkan jenis kelamin dan kelompok usia menunjukan bahwaperempuan usia 35-44 tahun memiliki angka pencabutan gigi permanen yang paling tinggi yakni 20 kasus dan yang paling rendah yakni perempuan kelompok usia 10-14 tahun 2 kasus dan laki-laki kelompok usia 10-14 tahun 8 kasus. Hasil yang serupa juga dilaporkan oleh Sanya tahun 2004 (Ni Wayan M, 2012) di Kenya, bahwa perempuan pada kelompok usia 35-44 tahun memiliki angka pencabutan gigi permanen yang paling tinggi yakni 69 kasus dan paling rendah ada di kelompok usia >65 tahun yakni 7 kasus. Meningkatnya angka pencabutan gigi permanen pada perempuan usia 35-44 tahun bisa dikaitkan dengan akumulasi deposit plak, kalkulus, peningkatan jumlah poket, resesi 
gingiva dan resorbsi tulang pada perempuan usia> 35 tahun.

Frekuensi pencabutan gigi permanen berdasarkan jenis kelamin dan indikasi gigi dicabut menunjukan bahwa perempuan memiliki frekuensi pencabutan gigi yang disebabkan penyakit periodontal lebih tinggi dibandingkan laki-laki yakni sebanyak 20 kasus. Jun Aida tahun 2006 di Jepang juga melaporkan hal yang sama yakni perempuan memiliki indikasi pencabutan gigi karena pernyakit periodontal yang lebih tinggi dibandingkan laki-laki. Perempuan (46,1\%) dan laki-laki (37,4\%). Proses ini berawal dari plak gigi pada wanita yang terdeposit kemudian berlanjut sampai terjadi penyakit periodontal. Selain itu faktor hormonal dapat berpengaruh sehingga kejadian penyakit periodontal pada wanita lebih tinggi. Adanya perubahan hormone seksual pada wanita yang berlangsung semasa pubertas dan kehamilan dapat menimbulkan perubahan jaringan gingiva yang merubah respon terhadap produk-produk plak. Namun bila masa pubertas dan kehamilan sudah lewat, inflamasi cenderung reda sendiri tetapi tidak hilang sama sekali, jika control plak tidak dilakukan dengan baik, akan terjadi akumulasi plak, kalkulus, peningkatan jumlah poket, serta mulai kehilangan jaringan dan resorbsi tulang sehingga dapat mengakibatkan pencabutan gigi permanen pada perempuan lebih tinggi dari pada laki-laki. (NiwWayan M, dkk, 2012)

Pencabutan gigi permanen berdasarkan usia pasien dan indikasi pencabutan memperlihatkan bahwa usia 35-44 tahun memiliki frekuensi pencabutan gigi karena penyakit periodontal yang paling tinggi yakni sebanyak 40 kasus. Hal yang sama juga dilaporkan oleh Nikolaos Andreas Chrysanthakopoulos di Yunani tahun 2011 bahwa pada kelompok usia 35-44 tahun, penyebab pencabutan gigi yang paling tinggi disebabkan oleh penyakit periodontal. Hasil ini sesuai dengan kepustakaan yang mengatakan bahwa penyakit periodontitis kronik menjadi indikasi kehilangan gigi pada usia >35 tahun karena telah terjadi akumulasi plak, kalkulus, resesi gingiva dan resorbsi tulang alveolar.

\section{KESIMPULAN}

Berdasarkan hasil penelitian yang dilakukan di Puskesmas Kaluko Bodoa Kota Makassar dapat disimpulkan bahwa:

1. Prevalensi Pencabutan Gigi Permanen Berdasarkan Jenis Kelamin adalah perempuan lebih banyak melakukan tindakan pencabutan gigi permanen dibandingkan dengan laki-laki. Tindakan pencabutan gigi permanen terhadap perempuan sebanyak 45 $(60 \%)$ dan laki-laki sebanyak 30 (40\%).

2. Prevalensi Pencabutan Gigi Permanen Berdasarkan Usia Pasien adalah Kelompok usia 35-44 tahun memiliki frekuensi pencabutan gigi yang paling banyak yaitu 22 kasus $(29,3 \%)$, kemudian diikuti dengan kelompok usia 25-34 tahun 16 kasus (21,3\%), kelompok usia 45-54 tahun 12 kasus (16\%), kelompok usia 55-64 tahun 10 kasus $(13,3 \%)$, kelompok usia 15-24 tahun 8 kasus $(10,7 \%)$, kelompok usia $>65$ tahun 5 kasus $(6,7 \%)$ dan frekuensi pencabutan gigi yang paling rendah ada dikelompok usia 1014 tahun yaitu sebanyak 2 kasus(2,7\%).

\section{SARAN}

1. Meningkatkan upaya promotif dan preventif kepada masyarakat diwilayah kerjanya dengan tidak mengabaikan juga upaya kuratif melalui fasilitas-fasilitas kesehatan yang ada. Kontrol plak setiap 6 bulan perlu dilakukan oleh masyarakat yang ada di wilayah kerja Puskesmas Kaluku Bodoa Kota Makassar untuk meminimalkan kerusakan gigi permanen.

2. Kasus yang masih bisa dirawat, sebaiknya diberikan pengarahan kepada pasien yang 


$\begin{array}{lcr}\text { bersangkutan } & \text { agar mengutamakan } \\ \text { perawatan } & \text { sehingga } & \text { dapat } \\ \text { mempertahankan } & \text { gigi permanen } & \text { tetap } \\ \text { berfungsi di dalam rongga mulut. } & \end{array}$

\section{DAFTAR PUSTAKA}

Rasdianti Inra P, 2012, Faktor-Faktor Penyebab Penundaan Pencabutan Gigi Di Rsgmp Drg. Hj. Halimah Daeng Sikati Fkg Unhas Periode April - Mei 2013, Skripsi, Fakultas Kedokteran Gigi Universitas Hasanuddin, Makassar

Balaji SM. 2007, Textbook of oral and maxillofacial surgery. New Delhi: Elsevier.,p.167,213-5.

Besford, John, 1996. Mengenal Gigi Anda, Petunjuk Bagi Orang Tua, Edisi 2, Jakarta. hal : 127

Haghighat A, Kaviani N, Panahi R. 2008, Hemodynamic effects of $2 \%$ lidocaine with 1:80000 epinephrine in inferior alveolar nerve block. Dental Research Journal; Spring - Summer 2006: 3(1): 4

Herijulianti, 2002. Pendidikan Kesehatan Gigi, Jakarta. Hal : $100-101$

Herijulianti, 2009. IImu Pencegahan Penyakit Jaringan Keras dan Jaringan Pendukung Gigi, Jakarta. Hal : 25 dan $30-32$.

Hidayat, Rachmat, Astrid. 2016. Kesehatan Gigi \& Mulut. Yogyakarta: CV Andi Offer.

Hongini, Y. Aditiawarman. 2012. Kesehatan Gigi \& Mulut. Bandung: Pustaka Reka Cipta.

Inka J. Fenanlampir, Ni Wayan Mariati, Bernat Hutagalung, 2014, Gambaran Indikasi Pencabutan Gigi Dalam Periode Gigi Bercampur Pada Siswa SMP Negeri 1 Langowan, Jurnal e-GiGi (eG), Volume 2, Nomor 2, Juli-Desember 2014

Loekman M. 2007, Teknik dasar pencabutan gigi, Jurnal Ilmiah dan Teknologi Kedokteran Gigi;: 3(3): 82.

Longginus E, Kaunang WPJ, Juliatri, 2012, Tindakan Pemeliharaan Kesehatan Gigi Dan Mulut Siswa SD GMIM Di Desa
Wiau Lapi Barat. Manado: Dentire journal; Juni;1(1):27-34

Manson, 2010. Buku Ajar Periodonti Edisi 2, Jakarta. hal : 1, 67 - 75, dan 107

Marlimus, 2018, Gambaran Kesehatan Gingiva Ditinjau Dari Kebersihan Gigi Dan Mulut (OHIS) Pada Siswa Di SD Negeri 11 Palembang Tahun 2018, Poltekkes Kemenkes Palembang, Palembang

Ni Wayan Mariati, Jimmy Maryono, Wulan Agnesia Panelewen, 2012, Gambaran Pencabutan Gigi Permanen di Puskesmas Bitung Barat Kecamatan Maesa Kota Bitung Tahun 2012, Jurnal, Fakultas Kedokteran Universitas Sam Ratulangi, Manado

Notoatmodjo, S. 2014. Metodologi Penelitian Kesehatan. Jakarta: Rineka Cipta.

Notoatmodjo, S. 2014. Promosi Kesehatan Perilaku Kesehatan. Jakarta: Rineka Cipta.

Pedlar J, Frame JW. 2007, Oral and maxillofacial surgery. China: Churchill Living Stone Elsevier; p.15,27.

Rilly Sylvester Ngangi, Ni Wayan Mariati, Bernat S.P. Hutagalung, 2012, Gambaran Pencabutan Gigi Di Balai Pengobatan Rumah Sakit Gigi Dan Mulut Universitas Sam Ratulangi Tahun 2012, Fakultas Kedokteran Gigi Fakultas Kedokteran Universitas Sam Ratulangi, Manado.

Riskesdas, 2013, Badan Penlitian Dan Pengembangan Kesehatan Kementrian Kesehatan RI, Jakarta:

Sanghai S, 2009, Chatterjee P. A concise textbook of oral and maxillofacial surgery. New Delhi: Jaypee Publisher, p.67,91-2.

Trisye Sampakang, Paulina N. Gunawan, Juliatri, 2015, Jurnal, Status Kebersihan Mulut Anak Usia 9-11 Tahun Dan Kebiasaan Menyikat Gigi Malam Sebelum Tidur DiSDN Melonguane, Jurnal e-GiGi (eG), Volume 3, Nomor 1, Januari-Juni ; 1-6

Wray D, Stenhouse D, Lee D, Clark AJ, 2003, Textbook of general and oral surgery. Philadelphia: Elsevier; p.200-1. 